\title{
IMPROVING CONSTRUCTION SAFETY WITH VIRTUAL-DESIGN CONSTRUCTION TECHNOLOGIES - A REVIEW
}

\author{
SUBMITTED: May 2020
}

REVISED: April 2021

PUBLISHED: July 2021

EDITOR: Esther Obonyo

DOI: $10.36680 /$ j.itcon.2021.018

\author{
Muneeb Afzal, Research Assistant \\ Department of Architectural Engineering, United Arab Emirates University \\ muneeb.afzal@uaeu.ac.ae
}

Muhammad Tariq Shafiq, Assistant Professor (corresponding author) Department of Architectural Engineering, United Arab Emirates University muhammad.tariq@uaeu.ac.ae

Hamad Al Jassmi, Associate Professor Emirates Center for Mobility Research, United Arab Emirates University Department of Civil \& Environmental Engineering, United Arab Emirates University h.aljasmi@uaeu.ac.ae

SUMMARY: The construction industry is prone to major safety hazards owing to the complex and onsite nature of construction projects. Hence, construction researchers have been pursuing concepts, methods, and tools using advancing technologies to improve construction safety management. Subsequently, the rapid digitization of construction work practices is providing opportunities to improve construction safety. Research has revealed that construction safety management practices can benefit from the applications of virtual design construction technologies (VDC), such as building information modeling (BIM), virtual reality (VR), augmented reality $(A R)$, geographic information systems (GIS), and gaming technology. This study comprehensively reviews 191 research articles, published between 2010 and 2019, focusing on providing an overview of the implementation and application of VDC technologies for improving construction safety. The objective of this review is to critically collect and analyze applications of VDC technologies and present a holistic view of the features and functions of VDC technologies that can impact jobsite safety improvement in the construction industry. The review showed that VDC technologies can substantially improve construction safety. Emerging digital technologies, such as BIM, $V R, A R, G I S$, and gaming technologies can transform the traditional document-oriented safety procedures into digitalized safety practices allowing safety managers to visualize and analysis construction sites virtually to devise proactive safety measures and effective safety trainings. This study also highlights challenges such as research gaps regarding these digital tools that are currently impeding their widespread use in construction safety.

KEYWORDS: Virtual design construction (VDC); building information modeling (BIM); augmented reality (AR); virtual reality (VR); geographic information system (GIS); 4-D BIM; construction safety; digital design technology

REFERENCE: Muneeb Afzal, Muhammad Tariq Shafiq, Hamad Al Jassmi (2021). Improving construction safety with virtual-design construction technologies - a review. Journal of Information Technology in Construction (ITcon), Vol. 26, pg. 319-340, DOI: 10.36680/j.itcon.2021.018

COPYRIGHT: (C) 2021 The author(s). This is an open access article distributed under the terms of the Creative Commons Attribution 4.0 International (https://creativecommons.org/licenses/by/4.0/), which permits unrestricted use, distribution, and reproduction in any medium, provided the original work is properly cited. 


\section{INTRODUCTION}

The construction industry has paved the way toward the advancement of civilization. Irrespective of being one of the oldest human endeavours, few improvements have been made in this industry from the perspective of jobsite safety. The construction industry has the highest accident rates of any industry, a fact highlighted in many research studies (Abudayyeh et al., 2006; Waehrer et al., 2007; Zhang et al., 2011; Zhou et al., 2013; Zou et al., 2015; Zou et al., 2017; Mo et al., 2018). Despite efforts at the government level, the construction industry still records high numbers of employee injuries, incidents, and illnesses (Azhar, 2017). Although the recorded number of fatal injuries has slightly decreased in recent years (from 5190 in 2016 to 5147 in 2017) in the United States, the casualty rates still remain high (Bureau of Labor Statistics, U.S. Department of Labor, 2019). These high accident rates associated with the construction industry in comparison to others sectors (Melzner et al., 2014; Choe et al., 2017) such as manufacturing and production, are attributed to the fact that construction sites are less controllable than other sectors, where most tasks are predefined and repetitive (Ringen et al., 1995; Ganah et al., 2017). Various industries have improved their workflows by incorporating digital methods (Kizil et al., 2001; Lucas et al., 2008; $\mathrm{Ku}$ et al., 2011), whereas construction remains heavily dependent on human resources and thus more prone to safety threats.

The effects of these casualties have known socioeconomic impacts (Tixier et al., 2017). Moreover, the indirect costs of safety incidents amount to roughly six times the direct costs of the hazard itself (Chen et al., 1995).

One of the reasons for the occurrence of safety hazards is the lack of technological aids in determining potential threats (Choi et al., 2004). Although the construction industry is rapidly incorporating digital tools to modify its workflows - from initiation to design, execution, and closure - the industry is lagging when it comes to adapting these tools for construction safety purposes. Traditional means of ensuring safety have depended on the safety managers' observation, instinct, and expertise (Choudhry et al., 2008). Similarly, conventional safety-training learning modules have various insufficiencies that render them ineffective (Pereira et al., 2018). Typically, construction workers use their prior experience to ascertain and react to safety hazards. Hence, one of the most challenging tasks for the workers is to recognize and respond when they are exposed to potential threats and hazards that are difficult to predetermine as such threats are difficult to mitigate and can fail a well-designed safety program (Chen et al., 2014).

Many unknown factors undermine construction safety, such as those pertaining to weather, staffing, or procurement-related issues ( $\mathrm{Ji}$ and Leite, 2015). Majority incidents occur because of the particular nature of construction, human behavior, harsh workplace conditions, and lack of safety management (Koehn et al., 1995); e.g., underground construction has many complexities that might jeopardize safety during construction ( $\mathrm{Li}$ et al., 2018). In the construction industry, most accidents are recurrent (Kim et al., 2011). Human error, one of the factors hampering safety, is due to a lack of skill in hazard recognition (Mo et al., 2018). Personal safety equipment is a last-resort option for workers to protect themselves from safety hazards, and with the rising complexity of construction projects, there exists a need to devise design-specific safety strategies (Puerto and Clevenger, 2012).

The unpredictable and complex nature of the construction industry creates the need to embrace new technologies to effectively deal with various incidents (Malekitabar et al., 2016). Such incidents can be resolved using various technology-driven applications, such as building information modeling (BIM) and associated immersive technologies for the visualization and simulation of design and construction information. Where traditional methods for construction safety somewhat fail at alleviating hazards, the abovementioned technologies can be highly useful in improving the workers' ability of hazard recognition and safety planning and management, thereby reducing the chances of error resulting in an onsite catastrophe. Some authors have used the term "virtual design and construction (VDC)" within the reference of BIM applications, such as Volk et al. (2014), whereas others have referred VDC to include new technologies and management approaches for the organization, communication, and collaboration of design and construction information in construction projects (Kunz and Fischer, 2012). Elmualim and Gilder (2014) and Bosch-Sijtsema, (2013) have called VDC as virtual prototyping, predicting that these technologies can rapidly improve the architecture, engineering, and construction (AEC) industry. According to Zhou et al., (2013), VDC technologies involve BIM, four-dimensional (4D) computer-aided design (CAD), virtual reality (VR), and augmented reality (AR). This study adopts the definition of VDC from Zhou et al. (2013), but extends the scope to include geographic information systems (GIS) and gaming technology applications to evaluate the relevant potential of VDC for construction safety management applications. 
BIM provides a good platform where the design for safety can be proactively implemented to mitigate future hazards (Lopez and Clevenger, 2012). Research has revealed that BIM and other visualization tools have helped to identify, assess, and address safety hazards during the design phase (Malekitabar et al., 2016). Companies are now exploring innovative measures to improve safety in the workplace (Chen et al., 2013). Many incidents could be mitigated if appropriate actions were taken in hazard identification (Chen et al., 2013). Immersive technologies have proved beneficial for improving hazard recognition (Tixier et al., 2013). Preconstruction visualization training could help workers experience real-life hazard scenarios prior to actual construction. Such training could enhance the hazard-determination ability of workers by providing continual feedback throughout training in a realistic construction environment (Pereira et al., 2018). VDC technologies can thus improve the safety culture both on and off the construction site.

This review dissects research on the enhancement of construction safety via the incorporation of VDC technologies in recent years. This study directly addresses the work of researchers exploring future applications and that of academicians attempting to fill academic gaps. By rigorously studying prior-published papers and databases, we identified a clear trend of involving the aforementioned technologies in the construction industry in the last decade. This paper provides a state-of-the-art critical review of journal papers and conference proceedings published between 2010 and 2019 on the application of VDC technologies to improve safety conditions on construction sites. An abundance of literature is available on this subject, of which, few studies have addressed the issue of safety management using digitized practices with applications of VDC tools; however, the construction industry still lacks digitalized safety management practices. The impact of VDC technology application on jobsite safety management in construction, and resulting productivity poorly understood that forms the scope for this research Using previous studies, this paper aims to identify the features and functions of VDC technologies that can impact jobsite safety improvement in the construction industry. In the following sections, this paper discusses the research methodology, research gaps, and limitations for future work as well as present our overall conclusions.

\section{RESEARCH METHODOLOGY}

\subsection{Motivation and Aim}

Although the incorporation of VDC tools into the construction industry's conventional workflows has been improving over the years, significant improvements in processes and technology have occurred in the last decade. A comprehensive literature review of research on this subject over the last 10 years shows that most review papers (Zhou et al., 2012; Zhou et al., 2013; Skibniewski., 2014; Bhoir et al., 2015; Guo et al., 2017; Kassem et al., 2017; Li et al., 2018) written during the decade concerning the use of digital tools to improve construction safety, do not cover majority of the VDC technologies. This critical review paper, which covers major research work from the entire decade of 2010-2019, not only covers the exploratory nature and implementation of VDC technologies but also presents the challenges and research gaps for future work. This paper takes a holistic approach toward dissecting research work performed in the last decade.

\subsection{Review Methodology}

To achieve a well-organized and structured literature review, a three-stage review method was adopted. These three stages include (1) literature identification; (2) literature screening; and (3) literature eligibility. The research began by compiling all papers pertaining to the targeted timespan (the last decade, 2010-2019) into a database for the literature review. In the first step, keywords were entered into the online database. As per Zhou et al., (2013) visualization technologies involve BIM, 4-D CAD, VR, and AR. The present review extends to this allusion and includes technologies such as GIS (Bansal, 2011) and Serious Games (Gao et al., 2017) because of their increased usage in construction safety. As this paper aims to evaluate VDC tools to help improve construction safety and VDC encompasses multiple technologies, several keywords and different combination sets were used to collect a broad range of related articles. These combinations include 1) VDC and construction safety; 2) BIM and construction safety; 3) VR and constructions safety; 4) AR and construction safety; 5) GIS and construction safety; 6) Serious Games and construction safety; and 7) digital design technology and construction safety. To ensure that the review covers more aspects of construction safety, other combinations were also used with all the individual VDC tools such as (1) safety training; (2) safety management; and (3) safety planning. These searches were conducted through available online databases such as Google Scholar, Scopus, and Web of Science. This review includes research work published in peer view journals and conference proceedings and excludes book reviews, 
editorials, and online reports, ensuring that all considered papers have a similar analytical construct in terms of methodology ( $\mathrm{Li}$ et al., 2018). The scope of this review is restricted to a specific period (2010-2019) owing to the limitations of this review and to provide a more focused review of the related work.

Following the above methodology, 468 papers were identified to be within the theme and scope of this research. Regarding the repetition of publications across the three databases, nearly 100 articles were found across two or more databases; these repeated articles were discarded and the final eligible count for the publications was 368 . Next, these articles were screened for relevancy in accordance with the research theme (the use of VDC technologies to improve construction safety) based on their titles and abstract. In total, 67 articles were found whose title did not indicate construction safety or any VDC technology and these articles were thus excluded from the present research. Similarly, the remaining 301 publications were screened against relevancy in accordance with the theme of the review by reading their abstracts; if the abstract did not correlate with subject of applying VDC technology for improving construction safety, the corresponding studies were also excluded. Finally, to ensure that only relevant papers were included in this review, the content of the shortlisted articles was skimmed through, reducing the final count of included publications to 191 for further analysis. This research methodology is illustrated through a prism diagram (Fig. 1). The above-described three-step technique is sufficient for providing a considerable amount of significant state-of-the-art literature from which the present review could generalize findings and discern challenges for future works. Table 1 lists the number of related articles found in each of these databases.

\subsection{Data Analysis}

Table 2 shows the top 12 journals with numerous related papers published in them, respectively. Among these journals, three construction-technology-themed journals (Automation in Construction, Journal of Construction Engineering and Management, and Journal of Information Technology in Construction) have the highest number of relevant publications - 31, 8, and 6, respectively. Fig. 2 depicts the number of papers published in journals and conference proceedings during each year from 2010 to 2019. In 2010, two journal and seven conference papers were published in the given domain. This number increased in the next three years, when prior to 2014, this number was constant; i.e., in 2013-14, the same numbers of papers were published on the application of VDC technologies for improving construction safety. An equal number, i.e., 15 conference and 15 journal articles, were published in the year 2017, and this is the maximum number (i.e., 30 articles) of articles published between 2010 and 2019. The maximum number of journal articles, 17, were published in the year 2015. Post 2017, the trend decreased toward 2018 with 19 articles, and as the research was concluded in April 2019, only 4 articles were published and considered herein.

Table 3 classifies the various VDC technologies and lists the number of research papers pertaining to each technology. The table clearly indicates BIM and VR to be the most utilized technologies, with 96 and 18 associated publications, respectively. For this review, only technologies such as BIM, AR, VR, GIS, and Serious Games were considered. All other VDC technologies that might have helped in construction safety through different integrations are categorized as others. Comparing the countries with the most number of journal papers published pertaining to construction safety and technology, China leads with 30 publications, followed by the United States at 28 publications. Table 4 lists the number of research papers based on the country that published on the subject in the field of digital tools for safety improvement. These countries were followed by South Korea, the United Kingdom, and Germany with nine, seven, and four publications, respectively. These numbers explain the attention these countries are paying to improving technological adaptation and construction safety in their workflows.

TABLE 1. Number of research papers acquired through each database.

\begin{tabular}{lll}
\hline Serial number & Databases used & Number of related articles found \\
\hline 1 & Google Scholar & 130 \\
2 & Web of Science & 34 \\
3 & Scopus & 27 \\
\hline
\end{tabular}




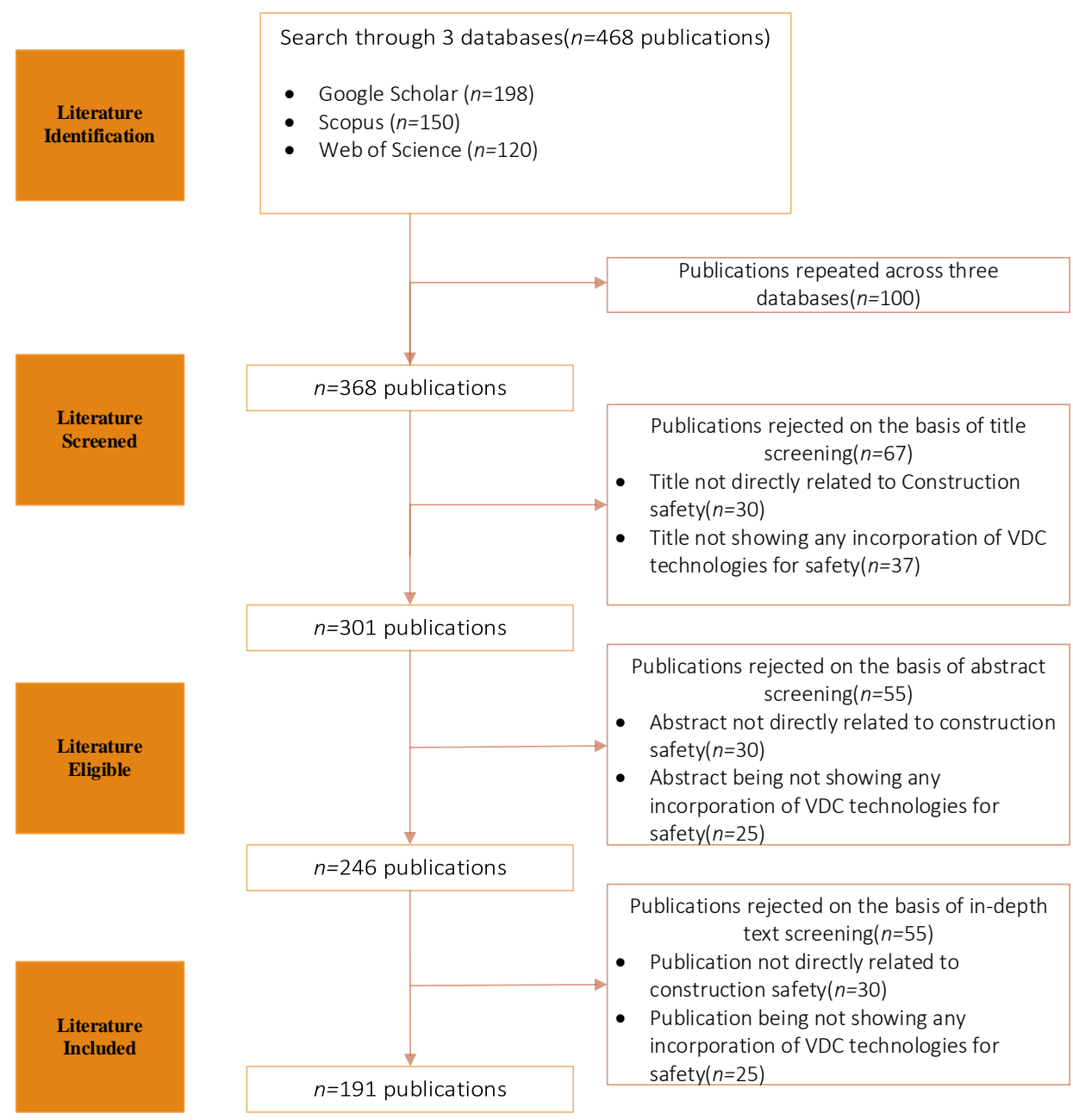

FIG. 1. Research paper selection and screening process

TABLE 2. Number of research papers published per journal.

\begin{tabular}{llll}
\hline $\begin{array}{l}\text { Serial } \\
\text { number }\end{array}$ & Name of Journal & $\begin{array}{l}\text { Number } \\
\text { related } \\
\text { articles }\end{array}$ & $\begin{array}{l}\text { of Imago } \\
\text { Journal } \\
\text { Rank }\end{array}$ \\
\hline 1 & Automation in Construction & 31 & 1.613 \\
2 & Safety Science & 11 & 1.113 \\
3 & Journal of Construction Engineering and Management & 8 & 1.023 \\
4 & Journal of Information Technology in Construction & 6 & 0.589 \\
5 & Construction Management and Economics & 5 & 0.816 \\
6 & Engineering, Construction, and Architectural Management & 3 & 0.653 \\
7 & Journal of Computing in Civil Engineering & 3 & 0.697 \\
8 & Advanced Engineering Informatics & 2 & 1.167 \\
9 & International Journal of Environmental Research and Public Health & 2 & 0.735 \\
10 & Journal of Civil Engineering and Management & 2 & 1.023 \\
11 & Journal of Engineering, Design, and Technology & 2 & 0.212 \\
12 & Sensors & 2 & 0.584 \\
\hline
\end{tabular}




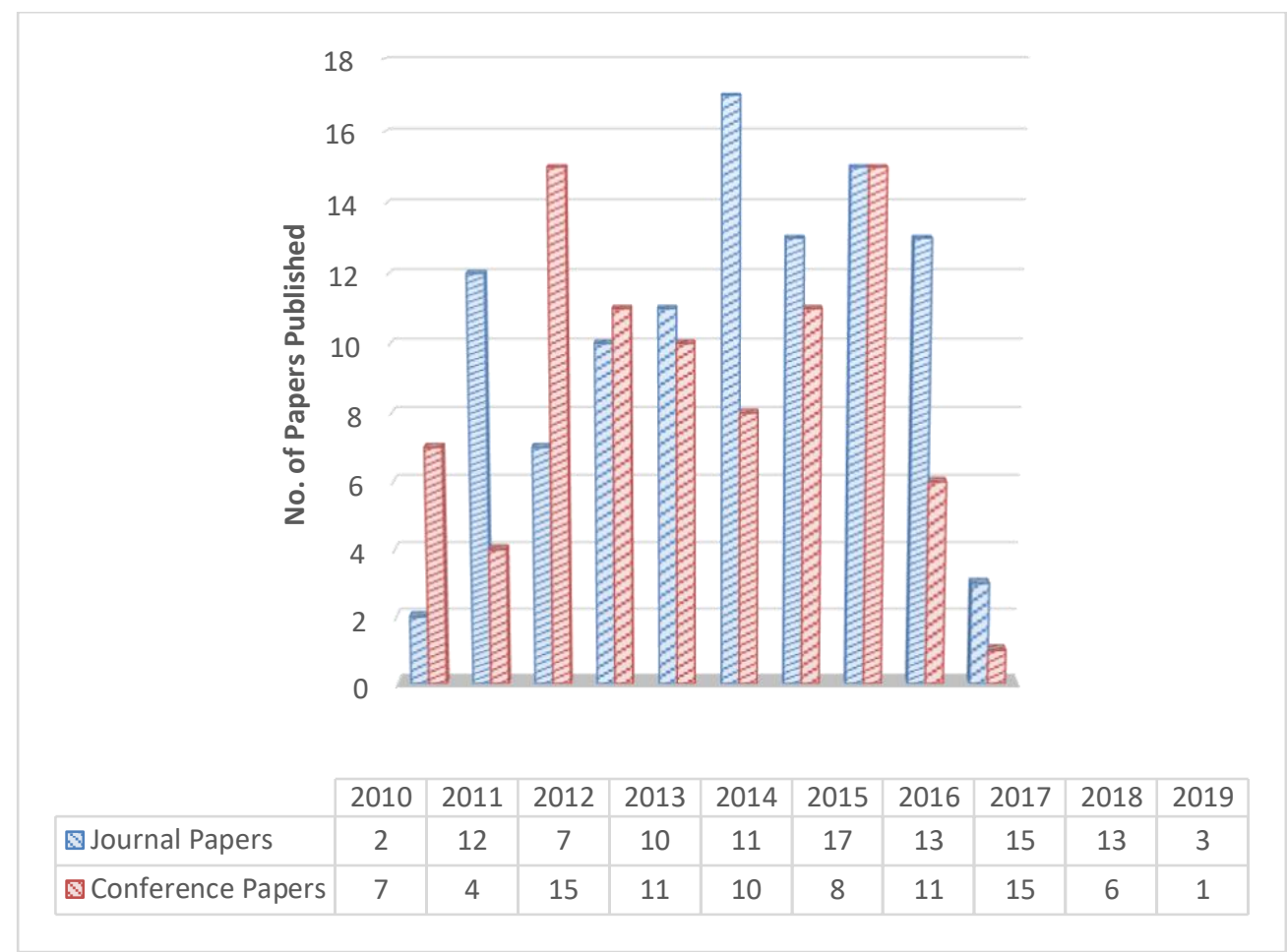

FIG. 2. Distribution of journal and conference papers published per year between 2010 and 2019

TABLE 3. No. of research papers published per individual VDC category

\begin{tabular}{lll}
\hline Sr. No. & Technology name & No. of Publications \\
\hline 1 & BIM & 96 \\
2 & AR & 11 \\
3 & VR & 18 \\
4 & GIS & 12 \\
5 & GPS, Drones, and other tracking systems & 15 \\
6 & Gaming, sensors, and web-based systems & 13 \\
7 & Others [Integration of different technologies to improve safety] & 26 \\
\hline
\end{tabular}

TABLE 4. Research papers published by country

\begin{tabular}{llll}
\hline Sr. No. & Country of origin & No. of publications & Rank \\
\hline 1 & China & 30 & 1 \\
2 & USA & 28 & 2 \\
3 & South Korea & 9 & 3 \\
4 & United Kingdom & 7 & 4 \\
5 & Germany & 4 & 5 \\
6 & Australia & 3 & 6 \\
7 & India & 3 & 6 \\
8 & Iran & 3 & 6 \\
9 & Israel & 3 & 6 \\
10 & Pakistan & 3 & 6 \\
\hline
\end{tabular}




\begin{tabular}{llll}
\hline Sr. No. & Country of origin & No. of publications & Rank \\
\hline 11 & Malaysia & 2 & 7 \\
12 & Brazil & 1 & 8 \\
13 & France & 1 & 8 \\
14 & Greece & 1 & 8 \\
15 & Lithuania & 1 & 8 \\
16 & Palestine & 1 & 8 \\
17 & Spain & 1 & 8 \\
18 & Turkey & 1 & 8 \\
19 & Vietnam & 1 & 8 \\
\hline
\end{tabular}

\section{VIRTUAL DESIGN CONSTRUCTION TECHNOLOGIES}

The construction industry is rapidly adopting latest technology inventions to improve existing construction practices, including VDC tools. According to Xu et al. (2014) and Bryde et al. (2013), VDC can help improve design quality, construction safety, and eventually reduce cost and save time. According to Azhar (2011), it can also improve productivity and project performance by improving the exchange of knowledge between stakeholders. These digital tools or VDC technologies are a set of information technology (IT)-based tools that help improve the efficacy of traditional workflows through digital or visual means. The set of technologies discussed in this section are BIM, VR, AR, GIS, and Serious Games. Previous research has explored the integration of different tools to evaluate their effectiveness to improve construction safety. Hence, some studies have considered other tools such as drones, sensors, RTLS, RFID, Cloud, and different Web Services and integrate different VDC tools to potentially improve construction safety.

\subsection{Building Information Modeling}

Among different VDC technologies, BIM is being used most prevalently. It is a technology-driven approach comprising an accurate digital model loaded with information used for planning, designing, construction, and facility operation that helps industry stakeholders to proactively visualize and detect issues through the entire project lifecycle (Azhar, 2011). Section 3.1.1 defines different aspects of BIM alongside other integrated technologies that could improve overall onsite safety.

\subsubsection{Building Information Modeling for Safety Planning and Management}

Efficient safety planning involves adopting proactive measures to mitigate both predictable and unpredictable sitesafety hazards. The traditional method for safety planning is prone to error and therefore untrustworthy. Because decision-makers use two-dimensional (2D) drawings to devise safety plans, visualizing site conditions and realtime scenarios is difficult. A BIM-based safety-planning approach-digitally designing and visualizing onsite conditions - can help safety managers devise better plans. Azhar (2017) validated the use of BIM to produce virtual simulations for safety planning and management. During our study, BIM proved significantly helpful for crane management, excavation risk management, fall protection during work on leading edges and roofs, and emergency-response planning. Similarly, Peng and Chua (2017) developed crane-information modeling for construction-site safety and layout based on data feeds and intended to address safe-lifting requirements. Their model contained information pertaining to the crane's lifting capacity, structure, and positional parameters, the configuration of the clear space on the construction site and methods to improve crane-related executional tasks.

To make decisions contributing to the improvement of safety and productivity of workers, Kim and Cho (2015) used an algorithmic approach and BIM to design temporary structures. Similarly, to improve productivity and safety, Chi et al. (2012) developed BIM-based components for use in temporary structures. The resulting models of scaffolds and formwork enabled safety experts to review them, resulting in better onsite decision making.

Malekitabar et al. (2016) presented a safety-risk identification and early-warning system to establish safety controls for underground-metro rail construction using BIM models. Both systems enhance risk-sharing and facilitate the reuse of risk-based knowledge. Along the same lines is the concept of job-hazard analysis (JHA), 
which, according to Zhang et al. (2015), is a process for automatically detecting potential safety incidents and then recommending measures to mitigate them. They devised a BIM-based JHA framework and compared it with JHA mechanisms traditionally used for safety planning. The BIM plugins used for JHA compiled more information for use in establishing better safety practices.

Most construction hazards occur mainly because of poor decisions made during the design-stage related to safety implications during the execution phase. This is where the application of BIM to include safety-related information within the design can help the overall safety management. BIM can contribute to construction-safety management in five ways: visualizing, coordinating, simulating, rendering, and optimizing (Xiong and Tang, 2017). BIM-based construction-safety management helps identify threat sources that can be considered during execution, thus improving the overall construction-safety environment.

Xiong and Tang (2017) devised a safety-management model merged with the construction schedule, a BIM model, and hazard analysis. That model performs safety-threat analysis and accordingly indicates proactive measures to avoid potential hazards. Similarly, Park and Kim's (2013) construction safety-management and visualization system (SMVS) integrates BIM, AR, location-tracking, and gaming technologies. SMVS architecture comprises three modules - planning, education, and inspection. Additionally, the visualization engine of SMVS manages and tracks information. The Microsoft XNA Game Studio 4.0 computer program was used to create the SMVS system architecture. SMVS enhances safety management by improving the stakeholders' planning, education, inspection, and time management. According to Chan et al. (2016), who developed a safety-information model, automation is the key to efficiency in safety management. Their model integrates properties, rules, schedules, and spatial information to help automate construction-safety management. Near-miss data active integrated with BIM could help with reporting and visualizing incidents. Shen and Marks (2016) used algorithms to analyze near-miss data for visualization by project stakeholders for better decision making. Near-miss reports and other data feeds need to be reviewed for correctness as they are exclusively based on observation, which is subject to human error in reporting.

\subsubsection{Building Information Modeling-based Design for Safety Framework}

Many construction accidents can be avoided if appropriate measures are implemented during the design phase. Because designers have only limited knowledge of construction safety, they are unable to foresee safety concerns throughout the construction operation and facility management (Hossain et al., 2018).

Engineers' focused experience can predict concerns based on their understanding of safety-related issues. Hayne et al. (2014) approached this problem by using a BIM-based design-for-safety framework. This digitally rectifying tool was incorporated into modeling software to efficiently produce safety models. Similarly, for better safety design, Hossain et al. (2018) presented a rule-based tool that has proven to be beneficial for assuaging risks; it comprises a risk register, a safety-design knowledge library, and an intelligent BIM risk-review system that includes case studies.

Many onsite safety incidents occur because temporary structures are not considered during design and safety evaluations. Kim et al. (2016) created a safety-planning platform that incorporates an automated safety-checking approach using BIM. Because their plug-in based on BIM and algorithms was able to detect safety hazards related to scaffolds, we consider it capable of helping to devise preventive measures for better temporary-structure safety planning.

\subsubsection{Building Information Modeling Applications for Rule-based Safety Checking}

Construction-safety planning still depends on manual observation and experience, which could be inaccurate, prone to error, and thus risky (Zhang et al., 2011). There exists a weak link between the activities of safety planning and execution in terms of accuracy and efficiency because the 2D drawings may not be relevant and the used software may have a limited sense of connectivity to the real world (Getuli et al., 2017). The implementation of automated safety-rule checking showed efficient use of time and staff for management, and the automated checking significantly helps prevent fall-hazard incidents (Zhang et al., 2013). Rule-based code checks validate safety design by comparing BIM models with codes and regulations (Getuli et al., 2017). Most of the time, research-derived automated rule checks are introduced either during the design phase or BIM modeling. Noting safety issues during the initial stages of a construction project could help address subsequent safety hazards. This not only helps with safety but it also helps optimize a project's cost and time parameters. 
A typical rule-checking system can be divided into four steps: first, a set of rules are written. Second, the objects within three-dimensional (3D) models and their associated parameters are considered. Third, rules are checked for compliance; both positive and negative values are noted for later return, wherein false values indicate rule conflicts. Fourth, received information is displayed in text format. The Solabiri Model Checker is commercial software that is used to measure 3D-model design quality and works by applying rule-based checking (Schwabe et al., 2016).

Li et al., (2018) devised a BIM-based three-step automated safety-risk recognition process: compiling a risk database, analyzing the link between engineering information and safety risks, and using BIM to automate safety recognition. Their research addressed technical, geological, and environmental risks. The incorporation of a safetyrisk recognition mechanism improves the efficiency and accuracy of collection and sharing of risk knowledge. Similarly, Zhang et al. (2011) incorporated an automated safety-checking tool, work-structure breakdown, and schedules in BIM to reduce the hazards on a project. Based on U.S. Department of Labor Occupational Safety and Health Administration (OSHA) rules, the desired outcome was achieved using Tekla Structures and Solibri Model Checker as software tools.

As projects become increasingly complex over time, it has become almost impossible to perform manual checks and validation. Zhang et al. (2012) developed a BIM-centric automatic safety-checking framework that automatically identifies hazards and indicates correction measures during the planning and design stages. They reported that the framework can help answer the questions of why, where, when, and what regarding fall-safety hazards before project execution. Takim et al. (2016) investigated a BIM-based automated safety-rule-checking system for fall hazards. The integration of BIM with this automated system benefited in three aspects: mitigating hazards, implementing safety regulations and best practices, and enhancing safety-rule checks throughout the project timeline. Getuli et al. (2017) devised a BIM-based health-and-safety (H\&S) design-validation system to fix safety issues during the design phase.

Fall from heights is one of the primary threats to safety. Zhang et al. (2015) identified and eliminated potential fall hazards by using an automated jobsite rule-checking framework. Applied in two case studies, their algorithms were able to indicate fall hazards associated with concrete slabs and edges. Consequently, after the automatically generated remedial plans were checked by a safety specialist, guidelines were implemented that could mitigate the revealed problems.

\subsubsection{Building Information Modeling Integration with Cloud, Sensors, and Real-Time Tracking Technologies}

BIM applications span a wide spectrum across industries, and BIM's easy use within traditional workflows and its various cross-disciplinary modules render it easy to integrate with other technologies.

Cloud technology, radio-frequency identification, and wireless sensor network integrate well with BIM; hence, they may prove to be beneficial for construction safety. For example, Bennett and Mahdjoubi (2013) explored the implications of integrating BIM with cloud technology for construction H\&S purposes. They suggested that although BIM and cloud technology implementation poses significant hurdles, successful execution can not only help with time and financials but can also improve safety conditions. The construction industry will eventually progress toward cloud computing for efficient communication and management purposes (Zou et al., 2017). Another system based on cloud technology is MapSafe. Its functions involve maintaining records from safety meetings, requests and approvals, safety analysis, and incident reports. The system itself is based on the integration of cloud computing, GIS, and mobile technology. The data captured through this system are subsequently processed in the cloud, and then the refined information is analyzed for rational safety-related decision making (Zou et al., 2017).

Wireless sensor network (WSN) is one of the technologies within the Internet of Things that senses objects and resonates environment-based conditions (Cheung et al., 2018). WSN comprises RF transceivers, microcontrollers, and power sources (Kiani et al., 2014). One of the significant reasons for onsite casualties is the harsh environment due to high temperature. Riaz et al., (2017) devised an H\&S management system to address this real-time worksite issue through live monitoring and visualization, which may help in proactive decision making to avoid any onsite mishap. For this purpose, their integration of Autodesk Revit Addin, WSN, and RFID resulted in a system that mitigates the threat of temperature-related onsite deaths. Similarly, Cheung et al. (2018) integrated BIM and WSN to monitor hazardous-gas conditions. For this purpose, wireless sensors were placed directly into an underground site and various environmental parameters such as temperature and humidity were measured to considered and 
were displayed via BIM models. The system was applied to a case study, and the proposed system promised to enhance efficiency in safety management. Similarly, Riaz et al. (2017) integrated BIM and WSN to evaluate realtime thermal conditions in congested workspaces. They applied a confined-space monitoring system, which integrated BIM-add-in and sensor data to solve construction-related safety problems.

RFID is an identification and data-collection technology that receives data via radio waves (Montaser and Moselhi, 2014). RFID technology involves three components: the RFID tag, the RFID reader, and the corresponding computer application (Sattineni and Azhar, 2010). An active RFID tag contains a battery and transmits signals within the range of the reader, whereas the passive tag does not have a battery and is active only within the range of the reader (Sattineni and Azhar, 2010). RTLS can be used to track actual locations of workers and construction equipment to give safety warnings (Setayeshgar et al., 2013). Costin et al. (2015) presented a method of real-time personnel tracking for safety monitoring by integrating BIM and RFID. The data thus produced can be used for resource tracking, data analysis, safety compliance, and safety violations. Zhang et al. (2013) developed a spatial network integrating BIM and RFID for safety management. They marked spaces with different risk levels and incorporated them into BIM. When workers wearing RFID tags enter the risky space, they are alerted regarding the situation. Sattineni and Azhar (2010) integrated RFID and BIM for tracking construction workers and onsite equipment to improve safety monitoring. They used Autodesk Revit as the software tool to work with RFID tags: the RFID reader receives radio signals from the worksite, and the information is stored in a database.

\subsection{Virtual Reality}

The need for VR in construction safety has emerged because the traditional approaches of safety-related capacity building do not meet the goal of inculcating students/workers with deep safety knowledge, hazard-identification skills, and real-life scenarios of construction-site safety issues. VR tools have been proven to help with these issues, increasing immersion and improving the understanding of real-life scenarios. VR is useful as a substitute for onsite training. Herein, we discuss the effectiveness of VR for improving different aspects of construction safety. VR lets us prepare for unforeseen safety challenges that commonly accompany different site-related mismanagement issues (Goulding et al., 2012). VR tends to increase engagement (Pena and Ragan, 2017); this is because the headsets provide the user with lifelike immersion (Froehlich and Azhar, 2016).

Teizer et al. (2013) integrated a real-time location system and VR for training iron workers. The fact that the training can be replayed as often as the trainee chooses makes it even more useful. Making a trainee aware of the safety measures that need to be taken to avoid any type of electrocution incident via conventional training methods of lectures and seminars is highly difficult. VR can be a very helpful tool for electrical-hazard recognition, given its lifelike feel that is ethically impossible to test (Zhao and Lucas, 2013).

The working mechanism for VR-based simulation is such that BIM-based models are imported into a gaming platform (e.g., Unreal Engine), and the final immersion is set to be observed via a head-mounted device (Hilfert et al., 2016). A user can experience immersion in two ways and both involve the use of a head-mounted VR device. In the first configuration, the person has screens placed next to the eyes, and in the second configuration, the user normally views two to three large projection screens. Such a setup is called a cave automatic virtual environment (CAVE; Jeelani et al., 2017). Sacks et al. (2015) focused on improving the collaboration between the design and execution teams working to improve construction safety by applying the CAVE system. CAVE-enabled VR-based experience allowed the teams to detect safety hazards when facing problems that are difficult to detect during onsite safety training with real-life hazards. CAVE systems expose the user to realistic - apparently unsafeconditions without endangering them in practice.

Many research studies on VR have compared the effectiveness of traditional training methods with modern VRbased immersive training. The lectures and videos involved in conventional training are not captivating enough for the user to be fully engaged. Pedro et al. (2016) compared the effectiveness of traditional training methods to that of a virtual safety-education system (VSES), a framework whose modules focused on safety-related training. Based on safety documents, the VSES comprised various safety scenarios projected in VR. The comparison clearly showed that VSES was superior for the students' understanding, knowledge, and grasping of safety concepts when compared to traditional training methods. Similarly, Sacks et al. (2013) revealed VR training to be a more effective mode of learning than classroom methods as it better held trainees' attention. Le et al. (2014) integrated VR and the Second Life game to provide safety training to students. The role-playing aspect of the game improved knowledge about safety-accident scenarios. One of the research modules had the students participate in groups, 
which promoted learning by incorporating real-time interaction. This training methodology in comparison with traditional classroom training was deemed more effective for learning. Mo et al. (2018) used a data-driven approach to address the issue of safety training, being very case-specific instead of holistic. Their data-driven approach automatically incorporates new construction-safety scenarios by extracting and analyzing information from the U.S. National Institute for Occupational Safety and Health database. For instance, 232 extracted cases were divided into clusters, and eight different parameters were analyzed to establish different scenarios that covered almost all types of construction hazards. The VR-based system, which was developed using the Unity 3D platform, provides immersion in real-life safety scenarios, but usually, the equipment requires increased energy consumption to run. Pham et al. (2018) provided a low-energy VR solution for construction-safety immersion. Their study compared interactive construction-safety education and 3D-VR immersive systems. The Samsung Gear VR-360-based construction-safety education system was found to consume less energy.

\subsection{Augmented Reality}

Similar to VR, AR is an immersive technology that helps users interact with environments that reflect the real world, but this technology projects digital images onto the real world. Thus, there is an interaction between real and digital space as digital imagery is projected onto the real world. AR appears to intermix the real world with virtual-world simulations (Yabuki and Tongthong, 2010). AR research shows evidence of potentially improving construction-safety practices by either improving the trainees' capacity building or by developing an AR-based framework for constructability analysis, ultimately improving safety.

Many studies in this regard are based on developing systems and prototypes to evaluate their potential for safety enhancement. One such AR system is the System for Augmented Virtuality for Environment Safety (SAVES), which was developed to address the lack of effectiveness of training modules (Chen et al., 2013). This system includes 68 training scenarios intended to test users in terms of their hazard-recognizing ability. Statistical analysis of user perceptions of the training showed SAVES to be similar to real-life scenarios, and the users believed that they improved their safety awareness by experiencing SAVES.

According to Chen et al. (2013), in the case of traditional training methods (involving lectures and videos), the audience tends to have a retention rate of $<20 \%$, whereas involvement in 3D-based exercises can increase that rate to $75 \%$. AR can train workers without exposing them to actual onsite dangers. With requisite AR-based training, workers were found to be less afraid of hazards and other safety threats including falls and slippage hazards, contact hazards, getting-stuck hazards, and household hazards (Chen et al., 2014). AR tends to improve the workers' hazard-determining skills. Immersion-based trainings allow the users to be more aware of an onsite safety hazard and hence avoid different types of consequential injuries.

Park and Kim (2013) approached safety improvement using a mix of technologies: BIM, RTLS, AR, and game technologies. SMVS is a framework aimed toward building the workers' capacity of mitigating safety risks and increasing stakeholders' communication. Similarly, Limsupreeyarat et al.'s (2010) research included hardware and equipment comprising a laptop, a video camera, and a head-mounted device. Databases of hazards, risks, consequences, and different scenarios were introduced to integrate the real- and virtual-world simulations.

The use of AR aims to confront the discrepancies that are part of traditional methods of safety training. Pereira et al. (2018) used panoramic AR tools to address fall-hazard threats in construction safety. The AR approach developed in their research aimed to improve employees' safety-related capacity building. OSHA and SGH trainings were used as reference materials to create $360^{\circ}$ panoramic images on an AR platform. Candidates testing the platform confirmed its ease of use and handling, stating that it helped them identify potential fall hazards. Alam et al. (2017) integrated mobile computing with VR and AR in an application used to determine safety-education challenges. Zhou et al. (2017) introduced an AR-based safety system for displacement inspection during tunnel construction, which promises to be a vital tool for inspection based on conducted experiments. Similarly, Talmaki et al. (2010) integrated geospatial data with AR-based referencing to provide operators with visual information on their surroundings, which can be very helpful for excavators and may minimize accident rates related to a collision or getting stuck. 


\subsection{Geographic Information System}

A GIS is an IT-based approach for capturing, storing, investigating, and displaying geographic information (Atay and Toz, 2012). It is a technology that can help evaluate spatial data and produce visualizations from such data in the form of maps. Research has leveraged the use of GIS to solve safety-related problems. Comprising information pertaining to both spatial and temporal domains, GIS is highly effective when used in safety planning and management. GIS captures and processes spatial data using computer graphics and database technologies; integrates spatial parameters that can be used for construction, financial administration, and overall habitat needs; and is a common key component of future decision making (Yu et al., 2012).

Any near-miss information can significant for worksite-safety management. If a worksite is analyzed properly and proactively, many near-miss casualties that occur for unknown reasons or because of negligence could be averted. Golovina et al. (2012) developed a method for near-miss safety incidents involving workers on foot and construction equipment. They analyzed spatial data and showed hazard indexes in the form of a heat map. Safety reports were generated through updated BIM models and through documents that report near-miss locations, environmental conditions, and types of equipment involved.

GIS can also be very useful for proper project site selection. According to Kumar and Bansal (2016), site selection for a building is often based on a stakeholder's judgment from prior knowledge and experience while ignoring safety aspects. Their research provides new insight for locating a safe construction site, and their GIS-based approach for selecting a building site ensures minimum costs, less environmental damage, and improved construction safety. GIS-based site planning could be highly useful for the whole project lifecycle. For example, Zhang et al. (2015) combined the use of GPS and BIM to visualize probable site hazards utilizing real-time site information. Similarly, Atay and Toz (2012) devised a system that uses spatial analysis to identify H\&S risks based on geography and safety regulations. Their system can develop an H\&S database, replace manual methods of extracting information, merge the H\&S data with spatial data, and thus help handle safety threats proactively. Once received, the data were examined for potential safety threats and for ensuring that adequate measures were implemented to minimize potential threats.

Planners integrate 2D drawings and schedules and devise space requirements for difficult tasks (Bansal, 2011). Through this integration, experts are able to foresee hazards that the site might experience from each activity. However, this process lacks the geospatial elements required for efficient planning. Some accident-prevention techniques in which GIS could be helpful include collecting scattered information, facilitating communication and data storage, and analyzing appropriate information (Manase et al., 2011). Jia et al. (2012) developed a monitoring system based on space visualization and characteristics using GIS technology. In addition, 4D modeling and geospatial parameters along with a safety database can help planners predict the when, where, what, and why of the required safety measurements (Zou et al., 2017). GIS can feed different databases and applications and thus improve decision making to help stakeholders. It has the capability to retain many types of information regarding the site, drawings, below-surface details, specifications, and landscaping.

Bi et al. [85] combined BIM and GIS to improve the knowledge on fire-related safety hazards. The fire-control system that they introduced proved helpful for site rescue and safety-hazard assessments after a burn. By providing its precise coordinate system, which BIM lacks, GIS can also contribute to safety, thereby mitigating identification errors and improving efficiency as well as saving time.

\subsection{Game Technologies}

Using game engines for skill development has attracted increasing research interest in the construction industry (Li et al., 2012). Gaming technology is currently being used in many other industries (such as defence, medicine, architecture, and education) for worker's skill development [13]. Games can provide real-life learning experiences for both field training and theoretical knowledge, e.g., through case scenarios (Mohd et al., 2019). Serious games offer users the opportunity to interact with simulated construction sites and develop skills accordingly (Miller et al., 2012).

Traditional training methodologies are ineffective at improving workers' hazard-identification capabilities. According to Dzeng et al. (2015), their hazard-identification game was better than traditional methods of learning ( $\mathrm{p}<0.001)$, and the same outcome of statistical analysis applied to the interest generated among students comparing traditional methods of learning (Dzeng et al., 2015). The 3D video game Safety Inspector made the 
students role play as safety inspectors to identify potential hazards. Torque 3D also was used as a game engine, and Autodesk 3DS Max and MilkShape 3D were used as 3D-modeling software tools (Lin et al., 2011). Li et al. (2012) formulated a virtual safety-assessment system that assessed workers based on their input regarding various virtual safety situations and provided feedback for them to improve their safety-related skills.

\subsection{Miscellaneous Virtual Design and Construction Technologies}

VDC includes many technologies, most of which address the enhancement of some aspect of safety, justifying their relevance to construction safety. For example, Melo et al. (2017) assessed the use of unmanned aerial vehicles (UAVs) for a safety inspection by collecting visual reports. Visual data help improve jobsite safety inspection. A database of photos and video recordings were collected by UAV at construction projects. Similarly, Fang et al. (2018) developed two convolutional neural network (CNN) models to determine whether the workers were wearing harnesses. Pictures of people working at heights were taken from different projects in China. The CNN was able to detect the workers not wearing harnesses but with $<100 \%$ accuracy. This VDC tool has great potential for site safety-control practices. Similarly, Irizarry et al. (2012) investigated the use of drone technology for construction-safety purposes. An aerial quadricopter was used in conjunction with a smart device to conduct operations traditionally performed by a safety manager. However, this application is a threat to onsite workers, and the application of this technology encountered social resistance.

Ho and Dzeng (2010) investigated the feasibility of using e-learning for construction safety, particularly regarding fall hazard. The e-learning mode is effective, as a worker can learn via media and repeat the learning procedure to reduce error and avoid injury. Similarly, Lin et al. (2014) developed an iPad application for safety inspections. Wang et al. (2015) developed a mobile phone application that reduces the demands on safety personnel. The safetyinspection system, which can facilitate good management decisions, comprises a safety checklist and key inspection methods to help make quick decisions. Li et al. (2015) conducted a pilot study using a proactive construction-management system, which they found was useful for automatically monitoring location-based behavior, measuring safety performance, investigating unsafe behaviors, and improving safety management.

\section{DISCUSSIONS ON FINDINGS AND FUTURE NEEDS}

After critically reviewing the research conducted over the last decade, this section discusses future gaps, challenges, and issues for VDC technologies derived from the literature that may become an essential part of construction-safety workflows; these factors are not only valid for research purposes but also have practical implications for widespread industrial application.

\subsection{Improvement in Immersive Devices}

Be it VR, AR, or mixed realities, major research development and improvement was continuously performed for all such technologies over the last decade. The head-mounted devices providing immersion have been refined with new features, allowing their improved versions to be introduced with fewer issues compared to earlier releases. A key problem with these devices is that they have a low field of view, resulting in immersion quality issues in addition to some users experiencing motion sickness (Luo et al., 2016). Immersive technology itself is well advanced today with increasing applications in different industries (e.g., healthcare), yet its application in the construction industry is relatively new, and the cost of equipment is high (Azhar, 2017). However, several companies are increasingly launching new head-mounted immersive devices; thish might establish enough competition in the market to improve user experience and lower prices (Hilbert et al., 2016). As for other types of required improvement, the device lacks real-world relevant feedback for use in safety training. Some new technologies are now available that can provide live feedback in response to an action performed while in immersion (e.g., the Teslasuit or haptic feedback suits). This aspect should also be studied in future research to record the feelings and reactions of a trainee, which would help us evaluate the extent to which these technologies can improve the safety-capacity building.

\subsection{Safety Training and Education}

Although technology has been highly effective in the case of immersion-based training or workers' capacitybuilding sessions for safety-based hazards, there are some issues with it. First, the training modules take a lot of time and effort to develop (Woksepp et al., 2005; Rüppel et al., 2011), rendering their implementation in real-time 
projects difficult as they may interfere with already tight deadlines. Second, most of the training modules developed in previous studies do not address safety hazards with a holistic approach (Malekitabar et al., 2016), and majority research either focuses on a specific hazard or does not address safety issues in detail, resulting in gaps in training. Third, the cost of creating these mock-up safety modules is very high (Whisker et al., 2013), and the implementation largely depends on whether all stakeholders are onboard. Even though it is known that safety is important, in many parts of the world even trivial measures are not implemented to fulfil safety standards. Thus, a system is required through which safety trainings address majority site-related issues and that is efficient in terms of both time and practicality.

\subsection{Lack of Study on Some Internal and External Factors}

Study of external factors, such as a harsh climate that can threaten construction safety, is largely lacking. Hence, research on how technology could help us mitigate safety threats that occur owing to both observed and unforeseen circumstances, such as unsafe weather conditions, is insufficient. Sensors with BIM could be very useful in assuaging such major issues. Additionally, some factors internal to the workers, such as psychological or cognitive factors, have not been widely addressed in studies even though VR and AR technologies have the potential to improve these aspects. This leaves a research gap for future studies using immersion-based technologies to help improve personal safety by providing inputs based on psychophysiological data.

\subsection{Generalizability and Repeatability of Digital Workflows}

Studies aimed toward introducing various prototypical frameworks or rule-checking engines are evaluations that address particular needs or aspects of safety (Malekitabar et al., 2016). To evaluate their effectiveness, such research must be applied to different construction projects over a span of time and in different regions (Rüppel et al., 2011). Research that is applied to a real-time project must be implemented with the utmost caution to ensure that it does not hamper a construction project in any manner. There is a definite need to use digital management and planning systems to determine whether, overall, they could improve daily construction-safety practices and whether the workflows are easily applicable and repeatable. They could help in not only reducing casualties but also in improving the time- and cost-related dynamics of the project.

\subsection{Integration of Traditional and Digital Safety Methodologies}

With the advancement of VDC technologies and the already-comprehensive research on construction safety, not many studies integrate traditional and advanced technologies to mitigate construction-safety hazards in the realworld environment. Traditional methods are highly experience-driven and require competencies of safety decisionmakers to devise and oversee safety plans, inductions, and other safety-related matters. The construction industry can significantly benefit from merging traditional hands-on training with digital approaches to improve worksite safety conditions. For example, Fang et al. (2014) provide an as-built framework for crane operators that considers the uniqueness of the given project. Most of the traditional safety learning is conducted in-situ; hence, this as-built approach to safety training can potentially assess and improve the workers' safety knowledge and practices. Similarly, the SVMS module devised by Park et al. (2013) integrates existing safety knowledge databases with $\mathrm{BIM}$, location tracking, AR, and game technologies to reduce field safety errors and channelize the communication between stakeholders.

\subsection{Technical Issues with Implementation of Digital Tools}

From the implementation perspective, BIM requires further investigation before it is fully a part of conventional construction, not only in developing countries but also in countries that already have made BIM an integral part of the legislation. Similarly, the interface of GIS tools is not very user friendly compared to software such as AutoCAD, which people have been using worldwide for decades. ArcGIS is a good software for spatial analysis. GIS needs to be integrated with other technologies to reap the maximum safety-related benefits. Moreover, workers need to be shown the materials, temporary structures, and equipment to have more meaningful interaction with the scenario or simulation. A user's age is also an issue while using the abovementioned technologies. The research is clear that with increased age, a person's intellectual ability decreases, and therefore, when using the software is taught to senior personnel, more effort and training may be required to extract maximum output and for the safety training to be effective (Pedro et al., 2016). GIS-or BIM-based prototypes are project-specific and do not consider 
generic usage (Choe et al., 2017). Their lack of a holistic approach makes them less useful in terms of construction safety. Data migration and the interoperability of these digital tools also requires improvement to become standardized methodologies (Rüppel et al., 2011). The main hurdles in successful data transfer are BIM's lack of both, a coordinate system and topological integration. BIM is intended to model components that do not exist, whereas GIS models components that do exist; hence more research is required to integrate BIM/CAD and GIS in terms of a spatial coordinate system.

\subsection{Technical Issues with Virtual-Reality Implementation}

Although VR has been used for construction safety in the past, capturing the truly complex and multi-hazard nature of a construction site is extremely difficult in immersion reality. Complex scenario development for gaming or training is a difficult and highly time-consuming task (Rüppel et al., 2011), requiring capital investment to develop the training curriculum. Creating VR case scenarios is labor intensive because VR-based scenarios require sophistication and dedication for development, without which, effectiveness suffers. Proper gadgetry and software modules are critical to for effective training. Additionally, the ease of usage in such VR-based environments is an issue. The data transfer is huge, which taxes the cable network (Luo et al., 2016) and replacing the system with mobile-based VR lowers the quality of immersion.

The hazards are case specific, and not every worker would require learning about some particular safety hazard. The devised programs or VR-based training modules are either hazard-specific or the built-in scenarios cover only a range of hazards rather than a comprehensive training module useful to everyone. As long as the trainees do not perform interaction themselves, there are few chances for learning, although they can identify hazards. However, to achieve effective learning, they must literally perform the task physically. The user needs tutorials while operating such devices, particularly workers who are less well versed in using computers and technology.

\section{CONCLUSIONS}

In this research, VDC technologies and their applications for construction safety have been evaluated. Those of the VDC technologies that were reviewed included BIM, VR, AR, GIS and Serious Games. This review dissected research work from the decade 2010-2019 because this is the time period in which the construction industry has seen technological intervention into conventional workflows. This in-depth review evaluated a total of 191 research papers, of which 103 were journal papers and the rest were conference papers. This comprehensive review of technological intervention discussed current challenges in the adoption of technology for improving construction-safety scenarios and related areas for future research.

The literature review showed that VDC technologies can substantially improve construction safety. In traditional methods of construction safety, decision-makers consult 2D drawings to produce safety plans. With the advent of BIM, visualizing, comprehending, and analyzing construction sites before execution and devising safety plans accordingly has become easier for decision-makers. Using 4D BIM, automated rule-checking methods, and intentional design for safety, probable hazards can be predicted, and preventive measures can be accordingly implemented. This research also explored applications of VR, AR, and GIS and evaluated their effectiveness in improving construction safety. Through immersive technology, trainees are exposed to scenarios and are provided training modules. The training aspect of using technology makes it better than conventional training methodologies, such that not only does it increase users' interest, but the retention span of trainees also increases compared to that observed in traditional methods. However, VR and AR use have yet to be proven from an industrial perspective. Similarly, GIS technology can also be helpful in construction safety, but its usage is not prevalent in the construction industry because of issues in its implementation. VDC technologies can play a significant role in safety management, planning, and visualization. Different frameworks have been devised that can help reduce onsite casualties. We also discussed the limitations and future research gaps. The technology has been well researched but has not been tried, tested, and validated sufficiently for industrial application. Moreover, the gadgets' immersive quality needs to be improved to provide the users with a more-lifelike immersion. Construction, particularly for small projects, redeems low gross profit margins and because of the general lack of awareness regarding latest digital technologies, the implementation of such technology in actual workflows is difficult, as previously highlighted by Sorrell (2003) and Hwang et al. (2014). The research findings of this review can be a useful reference contributing to future research and help in construction-safety improvement. 


\section{REFERENCES}

Abudayyeh, O., Fredericks, T.C., Butt, S.E., Shaar, A. (2006). An investigation of management's commitment to construction safety. Int. J. Project Management, 24, 167-174

Alam, M. F., Katsikas, S., Beltramello, O., Hadjiefthymiades, S. (2017). Augmented and Virtual Reality Based Monitoring and Safety System: A Prototype IoT Platform. Journal of Network and Computer Applications, 89, 109-119.

Atay, H., Toz, G. (2012). Spatial Analysis Based Health And Safety Risk Assessment For Linear Construction Projects. ISPRS - International Archives of the Photogrammetry, Remote Sensing and Spatial Information Sciences, XXXIX-B8, 77-82.

Azhar, S. (2011). Building information modeling (BIM): Trends, benefits, risks, and challenges for the AEC industry. Lead. Manag. Eng., 11, 241-252

Azhar, S. (2017). Role of visualization technologies in safety planning and management at construction jobsites. Procedia Engineering, 171, 215-226.

Bansal, V. K. (2011). Use of GIS and Topology in the Identification and Resolution of Space Conflicts. Journal of Computing in Civil Engineering, 25 (2), 159-171.

Bennett, L., L. Mahdjoubi, L. Construction Health and Safety, BIM and Cloud Technology: Proper Integration Can Drive Benefits for All Stakeholders. (2013).IEEE 5th International Conference on Cloud Computing Technology and Science, Bristol, pp. 215-218.

Bhoir, S., \& Esmaeili, B. (2015). State-of-the-Art Review of Virtual Reality Environment Applications in Construction Safety. Aei 2015. doi:10.1061/9780784479070.040

Bi, T., Wang, P., Zhang, Q. (2017). Design and Implementation of Digital Fire Control System Based on BIM and 3DGIS. Proceedings of the 2017 3rd International Forum on Energy, Environment Science and Materials (IFEESM 2017).

Bryde, D., Broquetas, M. \& Volm, J.M. 2013. The project benefits of Building Information Modelling (BIM). International Journal of Project management, 971-98

Bosch-Sijtsema, P. 2013. New ICT changes working routines in construction design projects. Nordic Academy of Management (NFF) Iceland, August 2013, 2013.

Bureau of Labor Statistics, U.S. Department of Labor. (2018). National Census of fatal occupational injuries in 2018. BLS. Retrieved from https://www.bls.gov/news.release/pdf/cfoi.pdf

Chan, I. Y. S., Leung, H. Y., Fung, I. W. H., Leung, M. (2016). How Can BIM support construction safety management? Development of SIM. MATEC Web of Conferences, 66, 00018.

Chen A., Golparvar-Fard, M., Kleiner B. (2013). SAVES: A safety training augmented virtuality environment for construction hazard recognition and severity identification, CONVR, 373-384.

Chen, A., Golparvar-Fard, M., Kleiner, B. (2013). Design and Development of SAVES: A Construction Safety Training Augmented Virtuality Environment for Hazard Recognition and Severity Identification. Comput. Civil Eng, 2013.

Chen, A., Golparvar-Fard, M., Kleiner, B. (2014). SAVES: An augmented virtuality strategy for training construction hazard recognition. Construction Research Congress 2014.

Chen, A., Mani, G., Brian M. Kleiner. (2013). SAVES: a safety training augmented virtuality environment for construction hazard recognition and severity identification.

Chen, J.-G., Fisher, D. J., Krishnamurthy, K. (1995). Development of a computerized system for fall accident analysis and prevention. Computers \& Industrial Engineering, 28, 457-466.

Cheung, W.F., Lin, T.H., Lin, Y.C. (2018). A Real-Time Construction Safety Monitoring System for Hazardous Gas Integrating Wireless Sensor Network and Building Information Modeling Technologies. Sensors, 18, 436. 
Chi, S., Hampson, K., \& Biggs, H.C. (2012). Using BIM for smarter and safer scaffolding and formwork construction: A preliminary methodology.

Choe, S., \& Leite, F. (2017). Construction safety planning: Site-specific temporal and spatial information integration. Automation in Construction, 84, 335-344. https://doi.org/10.1016/j.autcon.2017.09.007

Choi, H.H., Cho, H.N., Seo, J.W. (2004). Risk assessment methodology for underground construction projects. J. Construct. Eng. Manag., 130, 258-272.

Choudhry, R.M., Fang, D., Ahmed, S.M. (2008). Safety management in construction: Best practices in Hong Kong. J. Prof. Issues Eng. Educ. Pract., 134, 20-32.

Costin, A., Teizer, J., Schoner, B. (2015). RFID and BIM-enabled worker location tracking to support real-time building protocol control and data visualization on a large hospital project. J. Inf. Technol. Constr., 40, 495517.

Dzeng, R.J., Hsueh, H.H., Chang, R.N. (2015). 3D Game-Based Training System for Hazard Identification on Construction Site. 2015 12th International Conference on Fuzzy Systems and Knowledge Discovery (FSKD).

Elmualim, A. \& Gilder, G. 2014. BIM: innovation in design management, influence and challenges of implementation. Architectural Engineering and design management, 3-4, 183-199

Fang, Y., Teizer, J., \& Marks, E. (2014). A framework for developing an as-built virtual environment to advance training of crane operators. In Construction Research Congress 2014: Construction in a Global Network Proceedings of the 2014 Construction Research Congress (pp. 31-40). American Society of Civil Engineers. https://doi.org/10.1061/9780784413517.0004

Fang, W., Ding, L., Luo, H., Love, P. E. (2018). Falls from Heights: a computer vision-based approach for safety harness detection. Autom. Constr., 91, 53-61.

Froehlich, M.A., Azhar, S. (2016). Investigating virtual reality headset applications in construction. Proceedings of the 52nd Associated Schools of Construction Annual International Conference, April 13-16, Provo, UT.

Ganah, A.A. and John, G.A. (2017), "BIM and project planning integration for on-site safety induction", Journal of Engineering, Design and Technology, Vol. 15 No. 03, pp. 341-354. https://doi.org/10.1108/JEDT-022016-0012

Gao Y., González V. A., and Yiu T. W. (2017). "Serious Games vs. Traditional tools in Construction Safety Training: A Review." In: LC3 2017: Volume I - Proceedings of the Joint Conference on Computing in Construction (JC3), July 4-7, 2017, Heraklion, Greece, pp. 655-662. DOI: https://doi.org/10.24928/0070.

Getuli, V., Ventura, S. M., Capone, P., Ciribini, A. L. (2017). BIM-based code checking for construction health and safety. Procedia Engineering, 196, 454-461.

Golovina, O., Teizer, J., Pradhananga, N. (2016). Heat Map Generation for Predictive Safety Planning: Preventing Struck-by and near Miss Interactions between Workers-on-Foot and Construction Equipment. Autom. Constr., 71, 99-115.

Goulding, J., Nadim, W., Petridis, P., Alshawi, M. (2012). Construction Industry Offsite Production: A Virtual Reality Interactive Training Environment Prototype. Adv. Eng. Inform., 26, 103-116.

Guo, H., Yu, Y., \& Skitmore, M. (2017). Visualization technology-based construction safety management: A review. Automation in Construction, 73, 135-144.https://doi.org/10.1016/j.autcon.2016.10.004

Hayne, G., Kumar, B., Hare, B. (2014). The development of a framework for a design for safety BIM tool. Computing in Civil and Building Engineering.

Hilfert, T., Teizer, J., König, M. (2016). First Person Virtual Reality for Evaluation and Learning of Construction Site Safety. Proceedings of the 33rd International Symposium on Automation and Robotics in Construction (ISARC). 
Ho, C.-L., Dzeng, R.-J. (2010). Construction Safety Training via e-Learning: Learning Effectiveness and User Satisfaction. Computers \& Education, 55 (2), 858-867.

Hossain, M. A., Abbott, E. L., Chua, D. K., Nguyen, T. Q., Goh, Y. M. (2018). Design-for-Safety Knowledge Library for BIM-integrated safety risk reviews. Autom. Constr., 94, 290-302.

Irizarry J, Gheisari M, Walker BN. (2012). Usability assessment of drone technology as safety inspection tools. ITcon, 17(12), 194-212.

Jeelani, I., Han, K., Albert, A. (2017). Development of Immersive Personalized Training Environment for Construction Workers. Computing in Civil Engineering.

Ji, Y., Leite, F. (2015). Information representation schema for tower crane planning in building construction projects. Computing in Civil Engineering 2015.

Jia, N., Xie, M., Chai, X. (2012). Development and Implementation of a GIS-Based Safety Monitoring System for Hydropower Station Construction. Journal of Computing in Civil Engineering, 26 (1), 44-53.

Kassem, M., Benomran, L., \& Teizer, J. (2017). Virtual environments for safety learning in construction and engineering: seeking evidence and identifying gaps for future research. Visualization in Engineering, 5(1). https://doi.org/10.1186/s40327-017-0054-1

Kiani, A., Salman, A., Riaz, Z. (2014). Real-time environmental monitoring, visualization, and notification system for construction H\&S management. J. Inf. Technol. Constr., 19, 72-91.

Kim, H., Lee, H.-S., Park, M., Hwang, S. (2011). Information retrieval in construction hazard identification. 28th International Symposium on Automation and Robotics in Construction (ISARC 2011).

Kim, K., Cho, Y. (2015). BIM-based planning of temporary structures for construction safety. Comput. Civil Eng.

Kim, K., Cho, Y., Zhang, S. (2016). Integrating work sequences and temporary structures into safety planning: automated scaffolding-related safety hazard identification and prevention in BIM. Autom. Constr., 70, 128142.

Kizil, MS, and Joy, J.,(2001) "What can Virtual Reality do for Safety?” The University of Queensland, Minerals Industry Safety and Health Centre.

Koehn, E.E., Kothari, R.K., Pan, C.S. (1995). Safety in developing countries: professional and bureaucratic problems. J. Constr. Eng. Manag., 121, 261-265

Ku K, Mahabaleshwarkar P S (2011). Building interactive modeling for construction education in virtual worlds, ITcon Vol. 16, Special issue Use of virtual world technology in architecture, engineering and construction, pg. 189-208, https://www.itcon.org/2011/13

Kumar, S., Bansal, V. (2016). A GIS-Based Methodology for Safe Site Selection of a Building in a Hilly Region. Frontiers of Architectural Research, 5 (1), 39-51.

Kunz, J. \& Fischer, M. 2012. Virtual Design and Construction: Themes, Case Studies and Implmentation Suggestions. CIFE Working Paper no 97. Stanford University

Lai, Y.L., Chang, L.C., Liu, T.H. Sung, Y.C. and Yin, C.L., (2014). A novel RFID sensing system using enhanced surface wave technology for battery exchange stations, Mathemat. Probl. Engineeri.

Le, Q. T., Pedro, A., Park, C. S. (2014). A Social Virtual Reality Based Construction Safety Education System for Experiential Learning. J. Intel. Robotic Syst., 79 (3-4), 487-506

Li, H., Chan, G., Skitmore, M. (2012). Visualizing Safety Assessment by Integrating the Use of Game Technology. Autom. Constr. 2012, 22, 498-505.

Li, H., Lu, M., Hsu, S.-C., Gray, M., Huang, T. (2015). Proactive behaviour-based safety management for construction safety improvement. Safety Sci., 75, 107-117.

Li, M., Yu, H., Liu, P. (2018). An automated safety risk recognition mechanism for underground construction at the pre-construction stage based on BIM. Automat. Construct., 91, 284-292. 
Li, X., Yi, W., Chi, H.-L., Wang, X., \& Chan, A. P. C. (2018). A critical review of virtual and augmented reality (VR/AR) applications in construction safety. Automation in Construction, 86, 150-162. https://doi.org/10.1016/j.autcon.2017.11.003

Lucas, J. and Thabet, W. (2008), Implementation and evaluation of a VR task-based training tool for conveyor belt safety training, ITcon Vol. 13, Special Issue, Virtual and Augmented Reality in Design and Construction, 637-659

Luo, X., Wong, C., \& Chen, J. (2016). A Multi-player Virtual Reality-based Education Platform for Construction Safety.

Limsupreeyarat, P., Yabuki, N., Tongthong, T. (2010). Toward the Improvement of Safety Planning for Construction Activities Performed at High Elevation by Using Augmented Reality." In Computing in Civil and Building Engineering, Proceedings of the International Conference, vol. 30, Jun. 2010.

Lin, K.-Y., Son, J.W., Rojas, E.M. (2011). A pilot study of a 3D game environment for construction safety education. J. Inf. Technol. Constr. (Special Issue: Use of Gaming Technology in Architecture, Engineering and Construction) 16, 69-84 (2011)

Lin, K.-Y., Tsai, M.H., Gatti, U. C., Lin, J. J.C., Lee, C.H., Kang, S.C. (2014). A user-centered information and communication technology (ICT) tool to improve safety inspections. Autom. Constr., 48, 53-63.

Malekitabar, H., Ardeshir, A., Sebt, M. H., Stouffs, R. (2016). Construction safety risk drivers: A BIM approach. Safety Sci., 82, 445-455.

Manase, D., Heesom, D., Oloke, D., Proverbs, D., Young, C., Luckhurst, D. (2011) A GIS Analytical Approach for Exploiting Health and Safety Information. International Journal of IT in Construction, ITCon (16), 335356.

Melo, R. R. S. D., Costa, D. B., Álvares, J. S., Irizarry, J. (2017). Applicability of Unmanned Aerial System (UAS) for Safety Inspection on Construction Sites. Safety Science, 98, 174-185.

Melzner, J., Zhang, S., Teizer, J., \& Bargstädt, H.-J. (2013). A case study on automated safety compliance checking to assist fall protection design and planning in building information models. Construction Management and Economics, 31(6), 661-674. https://doi.org/10.1080/01446193.2013.780662

Merivirta, M-L., Mäkelä, T., Kiviniemi, M., Kähkönen, K., Sulankivi, K., Koppinen, T. (2011). Exploitation of BIM based information displays for construction site safety communication. In Proceedings of CIB W099 Conference: Prevention - Means to the End of Construction Injuries, Illnesses and Fatalities, Washington DC, USA. 2011. 30

Miller, G. A., Dawood, N. N., Kassem, M. (2012). Building an Emergent Learning Environment for Construction Health and Safety by Merging Serious Games and 4D Planning. Computing in Civil Engineering.

Mo, Y., Zhao, D., Du, J., Liu, W., Dhara, A. (2018). A Data-Driven Approach to Scenario Determination for VRBased Construction Safety Training, Construction Research Congress 2018.

Mohd, N. I., Ali, K. N., Bandi, S., Ismail, F. (2019). Exploring Gamification Approach in Hazard Identification Training for Malaysian Construction Industry. International Journal of Built Environment and Sustainability, 6 (1), 51-57.

Montaser, A., Moselhi, O. (2014). RFID indoor location identification for construction projects. Autom. Constr., 39, 167-179.

Park, C.-S., Kim, H.-J. (2013). A Framework for construction safety management and visualization system. Automat. Construct., 33, 95-103.

Pedro, A., Le, Q. T., Park, C. S. (2016). Framework for integrating safety into construction methods education through interactive virtual reality. Journal of Professional Issues in Engineering Education and Practice, 142 (2), 04015011 
Pena, A. M., Ragan, E. D. (2017). Contextualizing construction accident reports in virtual environments for safety education. 2017 IEEE Virtual Reality (VR).

Peng, L., Chua, D. K. (2017). Decision support for mobile crane lifting plan with building information modelling (BIM). Procedia Engineering, 182, 563-570.

Pereira, R. E., Gheisari, M., Esmaeili, B. (2018). Using panoramic augmented reality to develop a virtual safety training environment. Construct. Res. Congr. 2018.

Pereira, R. E., Moore, H. F., Gheisari, M., Esmaeili, B. (2018). Development and Usability Testing of a Panoramic Augmented Reality Environment for Fall Hazard Safety Training. Adv Informat. Comput. Civil Construct. Eng., 271-279.

Pham, H., Dao, N.-N., Kim, J.-U., Cho, S., Park, C.-S. (2018). Energy-efficient learning system using web-based panoramic virtual photoreality for interactive construction safety education. Sustainability, 10 (7), 2262.

Puerto, C.L., Clevenger, C.M. (2012). Enhancing Safety throughout construction using BIM/VDC.

Riaz, Z., Edwards, D.J., Parn, E.A., Shen, C., Pena-Mora, F. (2017). BIM and sensor-based data management system for construction safety monitoring. J. Eng. Des. Technol.

Ringen, K., Seegal, J., \& Englund, A. (1995). Safety and health in the construction industry. Annu. Rev. Public Health., 301(6760), 165-188. https://doi.org/10.1146/annurev.pu.16.050195.001121

Rüppel, U., \& Schatz, K. (2011). Designing a BIM-based serious game for fire safety evacuation simulations. Advanced Engineering Informatics, 25(4), 600-611. https://doi.org/10.1016/j.aei.2011.08.001

Sacks, R., Perlman, A., Barak, R. (2013). Construction safety training using immersive virtual reality. Construct. Manag. Econ., 31 (9), 1005-1017.

Sacks, R., Whyte, J., Swissa, D., Raviv, G., Zhou, W., Shapira, A. (2015). Safety by design: dialogues between designers and builders using virtual reality. Construct. Manag. Econ., 33 (1), 55-72.

Sattineni, A., Azhar, S. (2010). Techniques for tracking RFID tags in a BIM model. Proceedings--The 27th International Symposium on Automation and Robotics in Construction.

Schwabe, K., König, M., Teizer, J. (2016). BIM applications of rule-based checking in construction site layout planning tasks. Proceedings of the 33rd International Symposium on Automation and Robotics in Construction (ISARC).

Setayeshgar, S., Hammad, A., Vahdatikhaki, F., Zhang, C. (2013). Real-time safety risk analysis of construction projects using BIM and RTLS. Proceedings of the 30th International Symposium on Automation and Robotics in Construction and Mining (ISARC 2013): Building the Future in Automation and Robotics.

Shen, X., Marks, E. (2016). Near-miss information visualization tool for BIM. Construction Research Congress 2016.

Skibniewski, M. ł. J. (2014). Information Technology Applications in Construction Safety Assurance. Journal of Civil Engineering and Management, 20(6), 778-794. https://doi.org/10.3846/13923730.2014.987693

Takim, R., Zulkifli, M. H., Nawawi, A. H. (2016). Integration of Automated Safety Rule Checking (ASRC) System for safety planning BIM-based projects in Malaysia. Procedia-Social and Behavioral Sciences, 222, 103110.

Talmaki, S. A., Dong, S., Kamat, V. R. (2010). Geospatial Databases and Augmented Reality Visualization for Improving Safety in Urban Excavation Operations. Construction Research Congress.

Teizer, J., Cheng, T., Fang, Y. (2013). Location tracking and data visualization technology to advance construction ironworkers education and training in safety and productivity. Autom. Constr., 35, 53-68. 
Tixier, A. J. P., Hallowell, M. R., Rajagopalan, B., Bowman, D. (2017). Construction Safety Clash Detection: Identifying Safety Incompatibilities among Fundamental Attributes Using Data Mining. Automation in Construction, 74, 39-54.

Tixier, A.J.P., Albert, A. (2015). Teaching construction hazard recognition through high fidelity augmented reality. 2013 ASEE Annual Conference \& Exposition, 06-Jul-2015. [Online]. Available: https://peer.asee.org/22524.

Volk, R., Stengel, J. \& Schultmann, F. 2014. Building Information Modelling (BIM) for existing buildings Literature review and future needs. Automation in Construction, 109-127

Waehrer, G.M., Dong, X.S., Miller, T., Haile. E., Men Y. (2007). Costs of occupational injuries in construction in the United States. Accid Anal Prev., 39, 1258-1266

Wang, T., Fang, D., Li, G. (2015). Innovated safety inspection system on construction site based on mobile phone application. Proceedings of the 2015 International Symposium on Computers and Informatics.

Whisker, V. E., Baratta, A. J., Yerrapathruni, S., Messner, J. I., Shaw, T. S., Warren, M. E., Rotthoff, E. S., Winters, J. W., Clelland, J. A., \& Johnson, F. T. (2003). Using immersive virtual environments to develop and visualize construction schedules for advanced nuclear power plants. Paper presented at 2nd International Congress on Advances in Nuclear Power Plants, ICAPP 2003, Cordoba, Spain.

Woksepp, S., Jongeling, R., \& Olofsson, T. (2005). Applying virtual reality and 4D CAD models in the scheduling process of a large pelletizing plant. In Proceedings of CONVR 2005 : 5th International Conference on Construction Applications of Virtual Reality (pp. 352-360). Retrieved from http://urn.kb.se/resolve?urn=urn:nbn:se:ltu:diva-26777

$\mathrm{Xu}$, H., Feng, J. \& Li, S. 2014. Users-orientated evaluation of building information model in the Chinese construction industry. Automation in Construction, 39, 32-46

Xiong, N., Tang, J. (2017). Research on construction safety management based on BIM--Taking the Direction of Construction Engineering as an Example. Proceedings of the 7th International Conference on Management, Education, Information and Control (MEICI 2017).

Yu, Q., Jiang, J., Yu, H. (2012). Research on the Emergency Response System of Major Dangerous Chemical Accident on Highway Based on the GIS. Procedia Engineering, 45, 716-721.

Zhang, C., Chen, J., Yang, Y., Hammad, A. (2013). Experimental Investigation of using RFID Integrated BIM Model for Safety and Facility Management, in Proceedings of the 13th International Conference on Construction Application of Virtual Realty, CONVR, London, UK.

Zhang, J.P., Hu, Z.Z. (2011). BIM-and 4D-based integrated solution of analysis and management for conflicts and structural safety problems during construction: 1.Principles and methodologies, Automation in Construction, 20, 155-166.

Zhang, S., Boukamp, F., Teizer, J. (2015). Ontology-based semantic modeling of construction safety knowledge: towards automated safety planning for job hazard analysis (JHA). Autom. Constr., 52, 29-41.

Zhang, S., Lee, J., Venugopal, M., Teizer, J. and Eastman, C. (2011) Integrating BIM and safety: an automated rule-based checking system for safety planning and simulation. Paper presented at the CIB W099 Conference, Washington, DC, 24-26 August

Zhang, S., Lee, J.-K., Venugopal, M., Teizer, J., Eastman, C. M. (2012). A framework for automatic safety checking of building information models. Construction Research Congress.

Zhang, S., Sulankivi, K., Kiviniemi, M., Romo, I., Eastman, C. M., Teizer, J. (2015). BIM-Based Fall Hazard Identification and Prevention in Construction Safety Planning. Safety Sci., 72, 31-45.

Zhang, S., Teizer, J., Lee, J.-K., Eastman, C. M., Venugopal, M. (2013). Building Information Modeling (BIM) and Safety: Automatic Safety Checking of Construction Models and Schedules. Autom. Constr., 29, 183195. 
Zhang, S., Teizer, J., Pradhananga, N. (2015). Global Positioning System Data to Model and Visualize Workspace Density in Construction Safety Planning. Proceedings of the 32nd International Symposium on Automation and Robotics in Construction and Mining (ISARC 2015).

Zhao, D., Lucas, J. (2014). Virtual Reality Simulation for Construction Safety Promotion. International Journal of Injury Control and Safety Promotion, 22, 57-67.

Zhou, Y., Ding, L.Y., Chen, L.J. (2013). Application of 4D visualization technology for safety management in metro construction. Automation in Construction, 34, 25-36

Zhou, W., Whyte, J., \& Sacks, R. (2012). Construction safety and digital design: A review. Automation in Construction, 22, 102-111. https://doi.org/10.1016/j.autcon.2011.07.005

Zhou, Z., Irizarry, J., \& Li, Q. (2013). Applying advanced technology to improve safety management in the construction industry: a literature review. Construction Management and Economics, 31(6), 606-622. https://doi.org/10.1080/01446193.2013.798423

Zhou, Y., Luo, H., Yang, Y. (2017). Implementation of Augmented Reality for Segment Displacement Inspection during Tunneling Construction. Autom. Constr., 82, 112-121.

Zou, P. X., Lun, P., Cipolla, D., Mohamed, S. (2017). Cloud-based safety information and communication system in infrastructure construction. Safety Sci., 98, 50-69.

Zou, P.X.W., Sunindijo, R. (2015). Strategic Safety Management in Construction and Engineering. WileyBlackwell, UK. 240 pages. ISBN 9781118839379, 2015. 